\title{
MECHANICAL WEAR AND SURFACE ROUGHNESS OF GLASS AND HYBRID CERAMICS
}

\author{
Ahmad Khaled Abo El Fadl ${ }^{*}$
}

\begin{abstract}
Aim: The purpose of this invitro study was to evaluate wear resistance and surface roughness of two hybrid ceramics in comparison to lithium disilicate glass ceramic before and after mechanical abrasion.

Materials and methods: Thirty samples were divided according to material of construction into three groups, group (1): Lithium disilicate glass ceramic (IPS e.max, $n=10$ ), group (2): Resin nanoceramic (Lava Ultimate, $n=10$ ), group (3): Polymer infiltrated ceramic (Vita Enamic, $n=10$ ). All samples were fabricated out of CAD CAM ceramic blocks, weighed and evaluated for surface roughness before and after mechanical wear.

Results: Resin nanoceramic (Lava ultimate), showed significantly low weight loss and surface roughness change after mechanical wear than IPS e.max. The polymer infiltrated ceramic (Vita Enamic) showed significantly high surface roughness than Resin nanoceramic (Lava ultimate), while IPS e.max showed the highest weight loss and surface roughness change.

Conclusions: Resin nanoceramics revealed highest mechanical wear resistance contributed by terms of weight loss and surface roughness change, while Lithium disilicate glass ceramic showed the least wear resistance.
\end{abstract}

KEYWORDS: Wear, Surface roughness, Glass ceramics, Hybrid ceramics.

\section{INTRODUCTION}

Due to patient demands for better esthetics, direct composite restorations, which require minimal removal of tooth structure, are one of the treatment choices, however, their main disadvantages are low resistance to wear, discoloration and fractures. ${ }^{(1)}$ Ceramics are popular dental restorative materials because of their esthetic advantages, biocompatibility, and ability to yield smooth surfaces, which minimizes plaque adherence and subsequent periodontal inflammation.

Occlusal contact between antagonist's surfaces is a reason for wear and gradual removal of material.

* Lecturer of Fixed Prosthodontics, Faculty of Dentistry, Ain Shams University. Guest researcher, Oral technology Department, Bonn, Germany. 
Chewing, clenching and moisture cause mechanical wear of ceramic surface, which is assumed to be a reason for cracking or chipping of dental ceramics. ${ }^{(2)}$ Restorative materials should have sufficient mechanical properties and wear resistance to withstand chewing process and with low abrasive nature to opposing teeth and the material itself.

One popular ceramic is lithium disilicate glass ceramic which contains approximately $70 \%$ by volume needle-like crystals in a glassy matrix. This unique crystalline structure provides high edge strength, and fracture resistance allowing them to be finished to thin sections to be ideally used for veneers, inlays, onlays, posterior crowns and even for three-unit anterior bridges. ${ }^{(3,4)}$

Due to the continuous search for a better quality and properties in the field of dental CAD-CAM ceramics, newly introduced CAD/CAM Restorative hybrid ceramics; Vita Enamic and Lava Ultimate are available which are a direct result of using true nanotechnology in the dental field. They combine in their composition ceramic particles embedded in a polymeric matrix achieving a combination of properties of ceramics and composites, moreover such materials behave biomimetically due to physical properties similar to enamel and dentine that encourage ongoing studies on their microstructure, surface and mechanical properties. ${ }^{(5-10)}$

The consequences of ceramic degradation are coarseness of the exposed surface, increase in plaque accumulation and wear to antagonist materials or teeth. In addition, an increase in surface roughness of ceramics may decrease strength, and affect the clinical success of ceramic restorations. ${ }^{(11,12)}$

The complex nature of tooth wear leads to difficulties in conducting wear studies. Although, in vivo wear studies would seem ideal to evaluate the wear behavior of dental biomaterials, they are timeconsuming, expensive and the results scatter widely due to patient and dentist related factors. ${ }^{(13,14)}$
On the other hand, an in vitro wear study allows precise control of the environment and variables, which influence the wear process of dental hard tissues and biomaterials. ${ }^{(15)}$ However, there is no universally accepted wear testing method. Numerous wear simulation devices, developed for research purposes use different wear testing concepts and variables such as force, contact geometry and lubrication. ${ }^{(14)}$

The clinical performance of the new hybrid ceramics is still unknown and little is known regarding their mechanical wear resistance, therefore in this study the surface roughness and wear resistance of resin nano hybrid ceramics (Lava ultimate) and polymer infiltrated ceramics (Vita Enamic) were evaluated in comparison to a popular glass ceramic (IPS e.max).

\section{MATERIALS AND METHODS:}

In this in-vitro study, Thirty samples were divided according to material of construction into three groups, group (1): Lithium disilicate glass ceramic (IPS e.max, $n=10$ ), group (2): Resin nanoceramic (Lava Ultimate, $n=10$ ), group (3): Polymer infiltrated ceramic (Vita Enamic, n=10).

CAD/CAM blocks of the three materials were cut by Isomet precision microsaw into samples with $2 \mathrm{~mm}$ thickness each and verified using digital caliper as shown in figure 1.

For the IPS emax samples, the surface intended for wear test was finished to obtain smooth surface, then crystalized and glazed following the manufacturer instructions, while Vita Enamic and Lava ultimate samples were polished by polishing kit recommended for finishing and polishing of hybrid ceramics .For Vita Enamic, a special glaze was applied with fine brush evenly all over the surface and light cured for $60 \mathrm{sec}$. Afterward, all samples were cleaned in an ultrasonic cleaner, then weighed by a sensitive weighing scale accurate up to 0.0001 . 
Thirty freshly extracted upper premolars were selected to be used as antagonist. The extracted teeth were ultrasonically cleaned to remove any calculus or soft tissue remnants and then polished with non-fluoridated polishing paste and stored in saline solution. Each was embedded in a copper cylinder such that the cemento-enamel junction is $1 \mathrm{~mm}$ below the level a self-cure acrylic resin filling the cylinder where a serrated screw was inserted from the other side to help in positioning of the cylinder in a wear simulating machine as shown in figure 2 .

Specially constructed wear simulating machine at Oral technology department, Bonn University, Germany, was used to simulate 2-body wear between enamel and ceramic samples. The copper cylinder with the embedded premolar was fixed using the serrated screw to one compartment of the machine while the stainless steel plate holding the ceramic sample was fixed to the other compartment as shown in figure 2 .

Ceramic sample location was adjusted such that its center is facing the buccal cusp of the premolar, the machine was then run with a with the tip of syringe bump machine containing saliva substitute viscous solution directed toward the area of sample-premolar contact as shown in figure 3 . Samples were tested with vertical load of $50 \mathrm{~N}$ for 1. $2 \times 10^{5}$ cycles at a frequency of $1.6 \mathrm{~Hz}$ (lateral movement of $2 \mathrm{~mm}$ ) simulating a human chewing environment. ${ }^{(16,17)}$

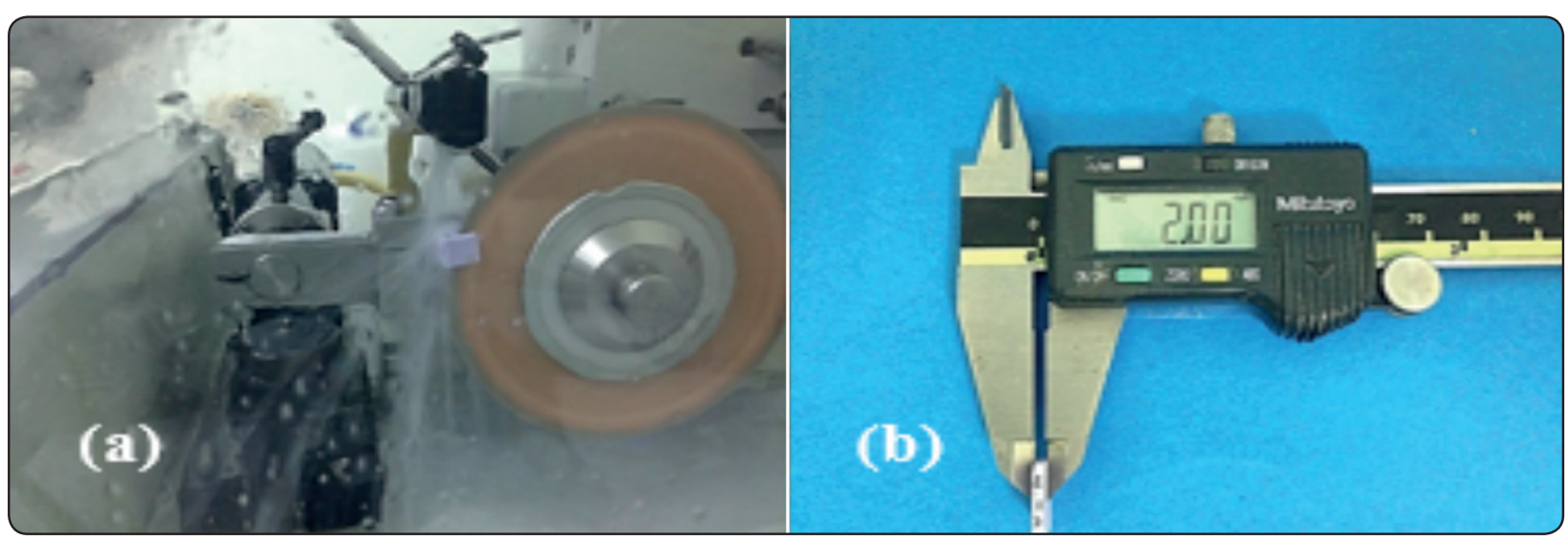

Fig. (1) Sample cut by isomet microsaw (a) and thickness verified by Digital caliper (b)

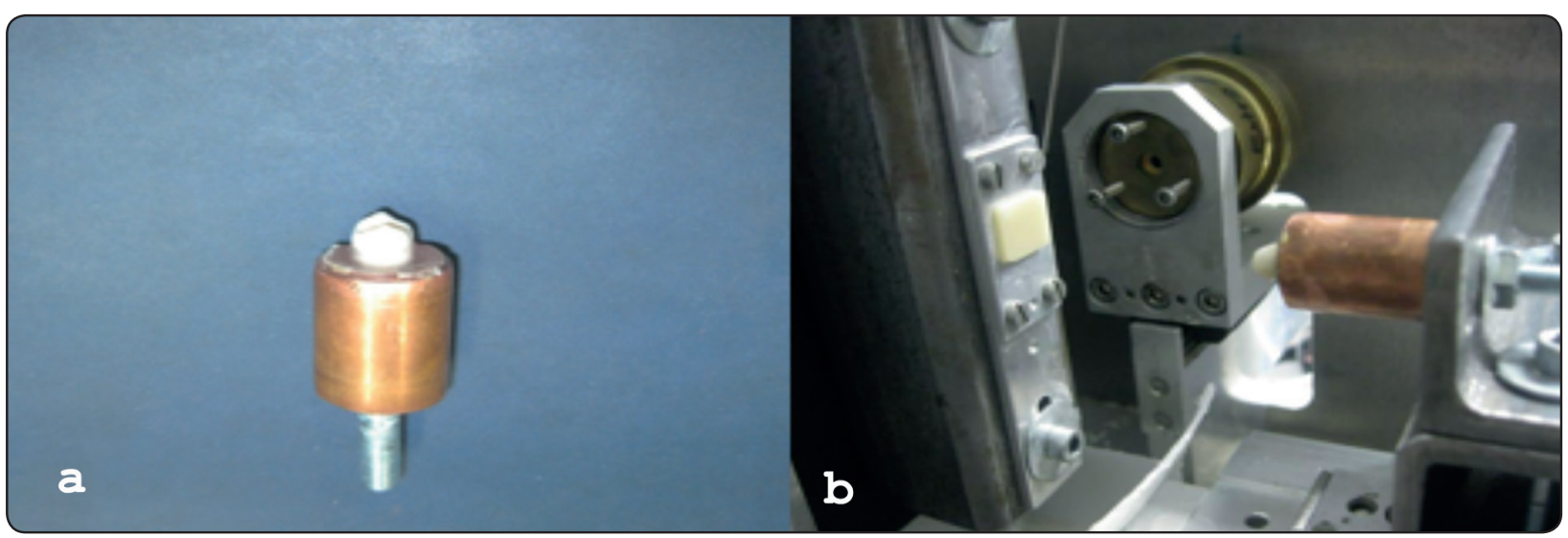

Fig. (2) Premolar in a copper cylinder (a) and the ceramic sample fixed to the wear machine (b) 
Quantitative analysis of two-body surface wear of ceramic samples and their antagonist enamel cusp samples was subjected to weight loss assessment and surface roughness $(\mathrm{Ra})$ change. ${ }^{(18)}$

Samples were reweighed after mechanical wear. Wear in a test sample was defined as the weight loss of samples to have occurred by subtracting initial weight from the final weight measurements. Surface roughness $(\mathrm{Ra})$ change was calculated using optical interference microscope (Interference Microscope, ZYGO Maxim-GP 200, ZYGO Lot GmbH, Boston, Middlefield, CT, USA). The occluding surface for each sample was scanned and the surface roughness was measured before and after the wear test as shown in figure 3

Data was collected, revised, coded, tabulated and statistically analyzed according to type of data obtained from each test .One way ANOVA and Bonferroni post-hoc were used to statistically analyze the tests results, and paired sample t-test was used to examine the effect of weight loss of each material.

\section{P- value: level of significance:}

- $\quad P>0.05$ : Non significant (NS).

- $\quad P \leq 0.05$ : Significant (S).

- $\quad \mathrm{P} \leq 0$. 01: Highly significant (HS).
The null hypothesis for the present study was that different types of glass-matrix and resin-matrix ceramics will not differ in their influence on their weight loss and surface roughness after wear test as a description of mechanical wear.

\section{RESULTS}

\section{Weight loss:}

IPS e. max showed highest amount of weight loss while Lava ultimate showed the least amount of weight loss. There was no significant difference between Vita Enamic and Lava ultimate $(P>0.05)$, also no significant difference between Vita Enamic and IPS e.max, but there was a significant difference between Lava ultimate and IPS e.max $(\mathrm{P} \leq 0.05)$ as shown in figure 4 and table 1.

\section{Surface roughness:}

IPS e. max showed highest amount of roughness followed by polymer infiltrated ceramic (Vita Enamic) while resin nano hybrid ceramic (Lava ultimate) showed the lowest surface roughness parameters. Roughness was significantly different between lava ultimate and Vita Enamic $((\mathrm{P} \leq 0.05)$, and between Vita Enamic and IPS e.max. , however it was found to be highly significant between Lava ultimate and IPS e.max $(\mathrm{P} \leq 0.01)$, as shown in figure5 and table 2.

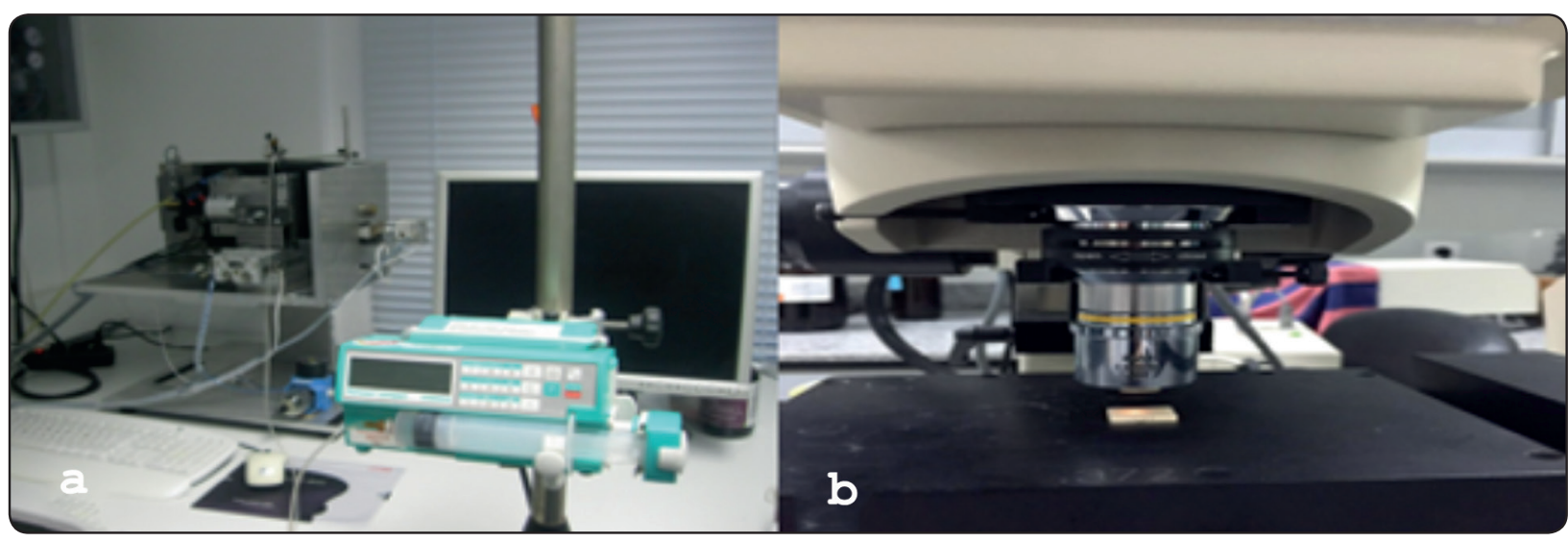

Fig. (3) Wear simulating machine with saliva substitute (a) and optical interference microscope (b) 
Optical interference microscope describes surface roughness by colored scale indicating elevations and depressions of the tested surfaces before and after mechanical wear.
Images obtained by optical interference microscope showed that IPS e.max presented the highest surface roughness showing more color scale variations followed by Vita Enamic while Lava Ultimate showed least variations as shown in figure 6.

TABLE (1) Mean and standard deviation of materials weight (in grams) before and after wear.

\begin{tabular}{|c|c|c|c|c|c|c|c|c|}
\hline & & \multirow{2}{*}{ Mean } & \multirow[b]{2}{*}{ \pm} & \multirow{2}{*}{ SD } & \multicolumn{2}{|c|}{ Paired Differences } & \multicolumn{2}{|c|}{ Paired Samples Test } \\
\hline & & & & & Mean & SD & $\mathrm{t}$ & P-value \\
\hline \multirow{2}{*}{$\begin{array}{c}\text { IPS } \\
\text { emax }\end{array}$} & Before & 0.657 & \pm & 0.003 & \multirow{2}{*}{0.027} & \multirow{2}{*}{0.035} & \multirow{2}{*}{2.404} & \multirow{2}{*}{$0.040 *$} \\
\hline & After & 0.630 & + & 0.036 & & & & \\
\hline \multirow{2}{*}{$\begin{array}{c}\text { Vita } \\
\text { Enamic }\end{array}$} & Before & 0716 & \pm & 0.009 & \multirow{2}{*}{0.018} & \multirow{2}{*}{0.019} & \multirow{2}{*}{2.870} & \multirow{2}{*}{$0.018 *$} \\
\hline & After & 0.698 & + & 0.024 & & & & \\
\hline \multirow{2}{*}{$\begin{array}{c}\text { Lava } \\
\text { ultimate }\end{array}$} & Before & 0.478 & \pm & 0.004 & \multirow{2}{*}{0.004} & \multirow{2}{*}{0.003} & \multirow{2}{*}{4.523} & \multirow{2}{*}{$0.001 *$} \\
\hline & After & 0.474 & \pm & 0.005 & & & & \\
\hline
\end{tabular}

TABLE (2) Mean and standard deviation for roughness parameter ( $\mathrm{Ra})$ of materials $(\mu \mathrm{m})$ after wear.

\begin{tabular}{|c|c|c|c|c|c|c|c|c|}
\hline & & \multirow[b]{2}{*}{ Mean } & \multirow[b]{2}{*}{ \pm} & \multirow[b]{2}{*}{ SD } & \multicolumn{2}{|c|}{ Paired Differences } & \multicolumn{2}{|c|}{ Paired Samples Test } \\
\hline & & & & & Mean & SD & $\mathrm{t}$ & P-value \\
\hline \multirow{2}{*}{$\begin{array}{c}\text { IPS } \\
\text { emax }\end{array}$} & Before wear & 0.710 & \pm & 0.321 & \multirow{2}{*}{0.021} & \multirow{2}{*}{0.263} & \multirow{2}{*}{0.252} & \multirow{2}{*}{0.807} \\
\hline & After wear & 0.689 & + & 0.252 & & & & \\
\hline \multirow{2}{*}{$\begin{array}{c}\text { Lava } \\
\text { ultimate }\end{array}$} & Before wear & 0207 & \pm & 0.054 & \multirow{2}{*}{-0.085} & \multirow{2}{*}{0.108} & \multirow{2}{*}{-2.486} & \multirow{2}{*}{$0.035^{*}$} \\
\hline & After wear & 0.292 & + & 0.095 & & & & \\
\hline \multirow{2}{*}{$\begin{array}{c}\text { Vita } \\
\text { Enamic }\end{array}$} & Before wear & 0.324 & \pm & 0.045 & \multirow{2}{*}{-0.339} & \multirow{2}{*}{0.253} & \multirow{2}{*}{-4.229} & \multirow{2}{*}{$0.002 *$} \\
\hline & After wear & 0.663 & \pm & 0.256 & & & & \\
\hline
\end{tabular}

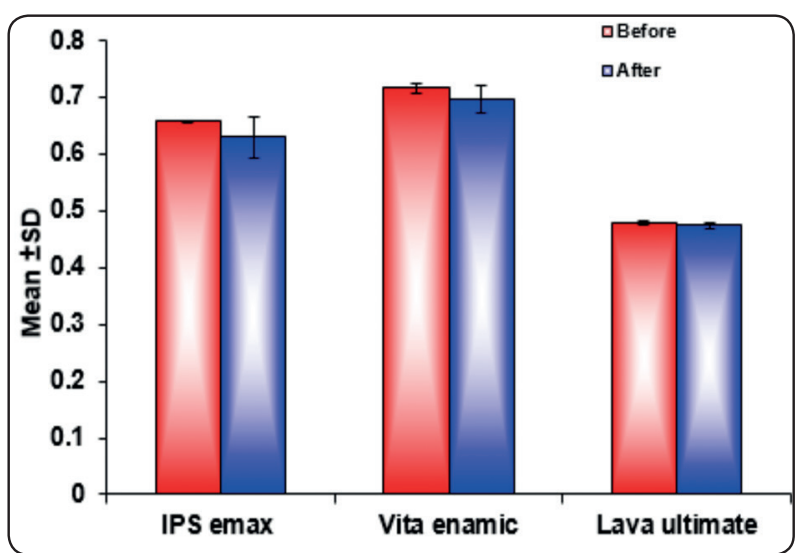

Fig. (4) Bar chart showing mean values of weight before and after wea.

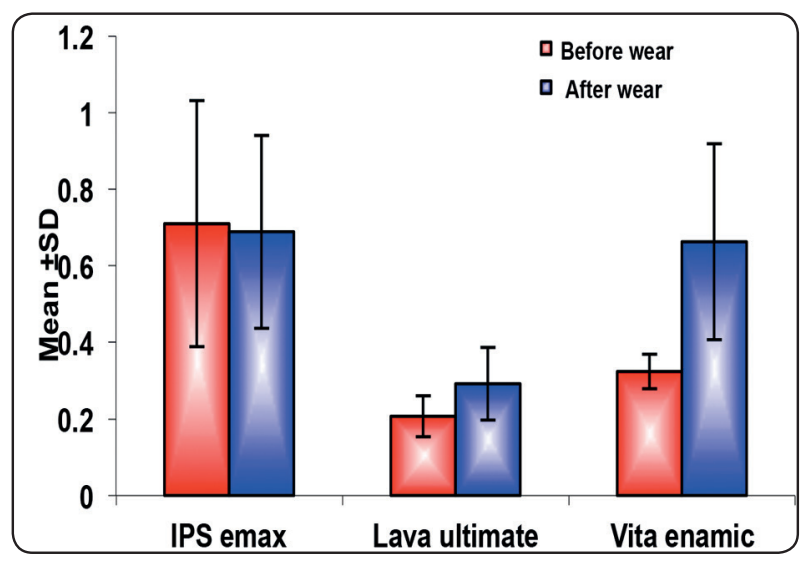

Fig. (5) Bar chart showing roughness before and after mechanical wear. 


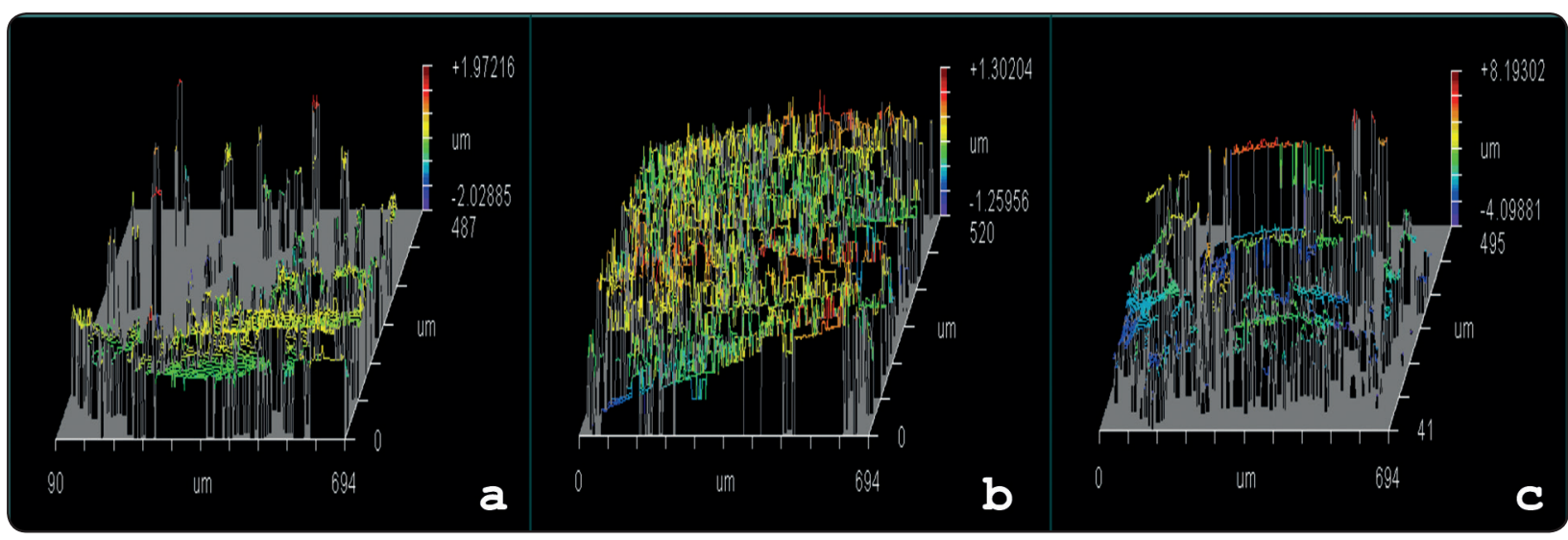

Fig. (6) Optical interference images of IPS emax (a), Lava Ultimate (b), and Vita Enamic (c) after mechanical wear

\section{DISCUSSION}

In oral cavity, restorative materials would be exposed to various chewing forces, temperature, moisture and parafunctional conditions which might affect their longevity and serviceability. Additionally smooth surface texture is critical to achieve color stability, strength and minimal wear to opposing teeth hence, the restorative materials should be selected to resist or have only little changes in these environments. This was in fact the rationale of our study.

Nowadays the success of recently introduced tooth colored materials and systems may be attributed to several factors, including technological advances and biomimitic properties which increase the move towards the avoidance of the use of metals in the mouth and their replacement with esthetic materials whenever possible.

Composites had been commonly used for years thanks to adhesive and elastic properties but unfortunately clinicians were faced with a lot of issues regarding their surface roughness and long term wear resistance, on the other hand recent ceramics provide more strength, color stability and better clinical performance. Those parameters drive the search for a new category of materials combining advantages of both and providing minimum wear of both restorative material and antagonistic tooth.
Lithium disilicate glass ceramic has been used for long time as clinically successful adhesive restoration based on long term clinical and laboratory studies which support its use as a standard for comparison with other newly introduced CAD/ CAM hybrid ceramics. ${ }^{(3,4)}$ Hybrid ceramics are a new category of ceramics where a combination of composite and ceramic properties was achieved aided by nanotechnology ,thus the purpose of this study was to evaluate the surface roughness and wear resistance of those newly developed CAD/ CAM hybrid ceramics after being subjected to mechanical abrasive forces.

Various tests (e.g. pin-on-block, three-body wear, toothbrush simulation) are available for investigation of wear performance of dental materials. ${ }^{(19)}$ In this study special wear simulating machine was used to simulate 2-body wear approach where a direct contact between enamel and ceramic sample takes place in the presence of saliva substitute. This approach was accepted by many studies as it simulates the clinical conditions including swallowing, para-function and dynamic occlusion movements, and can be described as a mixture of adhesion, attrition and fatigue wear. ${ }^{(20)}$

The obtained results are also of value in comparing materials under controlled conditions and predicting intraoral performance .There is no 
agreement among studies regarding the applied force, numbers of cycles, design and frequency, thus in the current study parameters of vertical load of $50 \mathrm{~N}$ for $1.2 \times 10^{5}$ cycles at a frequency of $1.6 \mathrm{~Hz}$ were selected according to previous studies. ${ }^{(16,17)}$

Many quantitative analysis methods of measuring the invitro wear of dental materials have been used. In our study, wear was evaluated in terms of weight losses and surface roughness of samples before and after wear as suggested by many authors. ${ }^{(18,21)}$

The results of this study revealed a statistically significant difference between IPS emax and lava ultimate in terms of weight losses and surface roughness change after wear, where the IPS emax showed the highest weight loss and surface roughness among all groups, while lava ultimate showed the least.

Regarding the wear behavior of IPS emax, results could be explained by their high friction coefficient which is in agreement with Heintze et al. ${ }^{(19)}$ Moreover, glaze layer of IPS emax might have been worn away during wear test leaving underlying rough surface exposed as also revealed by Ling Wang et al and Albashaireh et al, who reported that the wear behavior of polished IPS e.max has been lower to that of glazed one. The wear behavior observed by Albashaireh et al of the IPS e.max showed fragment loss with superficial and deep surface cracks giving sign of fatigue wear. It is also worth mentioning that the micro structure of IPS emax glass ceramic is not completely free of porosities and/or pores especially if crystallization was not ideally proceeded.$^{(22,23)}$

One more explanation might be densely packed crystals of such glass ceramic which when displaced from surface forms intermediate slurry that causes a three body wear leading to rougher surface. ${ }^{(24)}$

As for the results of lava ultimate showing the least wear, it might be due to nanofiller sized particles of the Lava ultimate that leave a smoother surface during abrasion. ${ }^{25)}$ Additionally, the material was formulated of blend of three fillers; zirconia and silica nanoparticles agglomerated into clusters, individually bonded silica nanoparticles and individually bonded zirconia nanoparticles, which reduces the interstitial spacing leading to a higher nanoceramic content, reinforced matrix and more wear resistance .

Comparing Vita Enamic with Lava Ultimate, there was no significant difference in weight loss which might be attributed to the fact that both are hybrid ceramics with elastic modulus and wear behavior matching to opposing enamel .Such results are going well with Mormann et al who reported low wear loss for Vita Enamic and Lava Ultimate in their two body wear study. ${ }^{(26)}$

On the other hand there is statistically significant difference in roughness between Lava ultimate and Vita Enamic which might be due to the latter being an interpenetrating phase ceramic composed of porous ceramic core infiltrated with resin, so the weaker polymer matrix might be easily separated from ceramic network resulting into higher roughness values. ${ }^{(27)}$ In addition, this might be also explained by the special glaze layer being worn away from the Vita Enamic surface as previously discussed with IPS emax.

\section{CONCLUSIONS}

Within the limitations of this study:

- Resin nano ceramics (lava ultimate) showed the highest mechanical wear resistance while lithium disilicate (IPS e.max) showed the least in terms of weight loss and surface roughness.

- Resin nano ceramics (lava ultimate) presented smoother surface by abrasive wear than polymer infiltrated ceramic (Vita Enamic). 


\section{REFERENCES}

1. Hickel R, Heidemann D, Staehle HJ, Minnig P, Wilson NH. Direct composite restorations extended use in anterior and posterior situations. Clin Oral Invest. 2004; 8: 43-4.

2. Coelho PG, Bonfante EA, Silva NR, Rekow ED, Thompson VP. Laboratory simulation of Y-TZP all-ceramic crown clinical failures. J Dent Res 2009; 88:382-386

3. Höland W, Schweiger M, Frank M, Rheinberger V. A comparison of the microstructure and properties of the IPS Empress 2 and the IPS Empress glass-ceramics. J Biomed Mater Res. 2000;53(4):297-303.

4. Kheradmandan S, Koutayas SO, Bernhard M, Strub JR. Fracture strength of four different types of anterior 3-unit bridges after thermo-mechanical fatigue in the dual-axis chewing simulator. J Oral Rehabil. 2001;28(4):361-369.

5. He LH, Swain M. A novel polymer infiltrated ceramic dental material. Dent Mater.2011; 27:527-534.

6. Della Bona A, Corazza PH, Zhang Y. Characterization of a polymer-infiltrated ceramic-network material. Dent Mater. 2014; 30(5):564-9.

7. Chaimongkon Peampring. "Restorative management using hybrid ceramic of a patient with severe tooth erosion from swimming: A Clinical Report". The Journal of Advanced Prosthodontics 2014; 6(5): 423-426

8. Koizumi H, Saiki O, Nogawa H, Hiraba H, Okazaki T, Matsumura H. "Surface roughness and gloss of current CAD/CAM resin composites before and after toothbrush abrasion". Dent. Mater. J. 2015; 34(6):881-7.

9. Alberto A, Pascual A, Camps I, Grau-Benitez M. "Comparative characterization of a novel Cad-Cam PolymerInfiltrated-Ceramic-Network". Journal of Clinical and Experimental Dentistry.2015;7(4): e495-e500.

10. Kamonkhantikul K, Arksornnukit M, Lauvahutanon S, Takahashi H. "Tooth brushing alters the surface roughness and gloss of composite resin CAD/CAM blocks". Dent. Mater. J. (2016); 35(2): 225-232.

11. Jakovac M, Zivko-Babic J, Curkovic L, Carek A. Chemical durability of dental ceramic material in acid medium. Acta Stomatol Croat. 2006; 40(1): 65-71

12. Goodacre CJ, Bernal G, Rungcharassaeng K, Kan JY. Clinical complications in fixed prosthodontics. J Prosthet Dent.2003; 90(1): 31-41

13. Sulong MZ, Aziz RA. Wear of materials used in dentistry: a review of the literature. J Prosthet Dent. 1990; 63(3): 342-349.

14. Heintze SD. How to qualify and validate wear simulation devices and methods. Dent Mater. 2006; 22 (8):712-734.
15. Lambrechts P, Debels E, Van Landuyt K, Peumans M, Van Meerbeek B. How to simulate wear? Overview of existing methods. Dent Mater. 2006; 22:693-701.

16. Lazaridou, D.; Belli, R.; Krämer, N.; Petschelt, A.; Lohbauer, U. Dental materials for Primary dentition: Are they suitable for occlusal restorations? A two-body wear study. Eur. Arch. Paediatr. Dent. 2015; 16 (2)165-172.

17. D’Arcangelo, C.; Vanini, L.; Rondoni, G.D.; Pirani, M.; Vadini, M.; Gattone, M.; De Angelis, F. Wear properties of a novel resin composite compared to human enamel and other restorative materials. Oper. Dent. 2014; 39, 612-618.

18. Adriana Claudia. New resistance of pressable low fusing ceramic opposed by dental alloys. $J$ of mechanical Behaviour Of biomedical material. 2014; 32: 46-51.

19. Heintze SD, Cavalleri A, Forjanic M, Zellweger G, Rousson V (2008) Wear of ceramic and antagonist-a systematic evaluation of influencing factors in vitro. Dent Mater 24:433-449

20. Ghazal M, Yang B, Ludwig K, Kern M. Two body wear of resin and ceramic denture teeth in comparison to human enamel. Journal of dental material 2008; 24(4):502-7.

21. Prakki A, Cilli R, Amarante de Araújo P, Navarro MF, Mondelli J, Mondelli RF. Effect of tooth brushing abrasion on weight and surface roughness of $\mathrm{pH}$-cycled resin cements and indirect restorative materials. Quintessence Int.2007; 38: 544-554.

22. Lin Wang A., Yihong Liu A., Wenjie Si B., Hailan Feng A., Yongqing Tao A., Zhizuo Mac. Friction and wear behaviors of dental ceramics against natural tooth enamel. J of the European Ceramic Society 2012; 32: 2599-2606.

23. Albashaireh z. Two-body wear of different ceramic materials opposed to zirconia ceramic. J of prosth. Dent. 2010; 104 (2): 105-13.

24. Mair LH, Stolarski TA, Vowles RW, Lloyd CH.Wear: mechanisms, manifestations and measurement. Report of a workshop. J Dent.1996; 24:141-148.

25. Van Noort R, Barbour ME. Introduction to dental materials, 4th edition: Elsevier Health Science; 2013.

26. Mormanna W. H., Stawarczyk B., Endera A., Senerc B., Attinc T., Mehla A. Wear characteristics of current aesthetic dental restorative CAD/CAM materials: Two-body wear, gloss retention, roughness and Martens hardness. J o f mechan. Behave. Of biomedical materials. 2013; 20: 113-125.

27. Awad D, Stawarczyk B, Lebermann A, llie N, Translucency of esthetic restorative $\mathrm{CAD} / \mathrm{CAM}$ materials and composite resins with respect to thickness and surface roughness. J Prosthet Dent. 2015 Jun; 113(6):534-40 . 